Changing Societies \& Personalities, 2017

Vol. 1, No. 2

http://dx.doi.org/10.15826/csp.2017.1.2.012

\title{
ARTICLE
}

\section{Historical Responsibility, Historical Perspective}

\author{
Daria Tomiltseva \\ Ural Federal University, Yekaterinburg, Russia
}

\begin{abstract}
This article examines the problem of understanding historical responsibility in the context of historical perspective. The author questions what makes responsibility historical, in which ways responsibility can be written into a chronology and how the meaning of responsibility should be understood. Based on Agamben's reconsideration of Pilate's trial of Jesus, an analysis of the origins of contemporary dualism in understanding the responsibility of the metaphysical perspective of an unchanging semantic value and the variability of the requirements of contingent situations for the execution of an act is carried out. In addition, the article examines the relationship of responsibility for the past (primarily constituted through the prism of guilt and memory) and responsibility for the future as viewed in an instrumentalist vein and in the context of messianism. Historical responsibility can be conceptualised on the basis of an ontological approach to understanding responsibility (Heidegger, Levinas, Derrida, Nancy), according to which the connections of responsibility are not limited to imputations of obligations to recognise guilt, but rely on the fundamental basis of human activity. With this method of consideration, the historicity of responsibility does not lie in the localisation of certain events on time intervals, but rather is seen as the unfolding of the meaning of human deeds, thanks to which people, actions, intentions and ideas are organised into a single historical perspective. Historical relationships of responsibility are not limited by the time, space or social status of people, but are tied by the finitude of the existence of those whom they bind.
\end{abstract}

\section{KEYWORDS}

Responsibility, historical responsibility, past, messianism, history, chronology 


\section{Introduction}

Despite its relevance to political discourse, the topic of historical responsibility is not widely covered in contemporary Russian research. As such, it is rarely seen as a topic in its own right, but is instead raised in relation to issues of historical memory or national consciousness. Among recent interesting initiatives in this area, mention should be made of the proposal of the editorial board of the journal Historical Expertise "Global Memory: A Culture of Historical Responsibility in the $21^{\text {st }}$ Century" ("Global Memory", 2016, p. 10). The authors of the programme refer, in particular, to a possible direction for research in terms of an "investigation of the culture of historical responsibility, increasingly expressed in public apologies by political and public figures for crimes of the past" ("Global Memory", 2016, p. 10) and suggest the possibility of "the adoption of the concept of historical responsibility in the political culture of the $21^{\text {st }}$ century" ("Global Memory", 2016, p. 10).

When getting acquainted with the programme, the question arises as to whether such an understanding of historical responsibility is sufficient. After all, in the text presented, it is almost impossible to ascertain who should apologise to whom and for what; likewise, whether other gestures and practices are possible within the framework of a culture of historical responsibility and where is the limit after which sincere regrets and willingness to cooperate turn into mere politeness and cynical calculation? Of course, in this case, the main emphasis is placed on the concept of global memory, compared to which historical responsibility is something of an auxiliary practice: the discussion primarily concerns a project that points out vectors for further research. However, it should be noted that K. A. Pahluk (2016) asks questions similar to those expressed herein, but already applied to the concept of global memory.

Despite the text failing to present a detailed description of the concept of historical responsibility, it becomes clear that the discussion concerns itself with some practices of public acknowledgement of historical guilt and the ability and willingness to participate in discussion and a rethinking of the past. Since the second half of the twentieth century, such practices have increasingly become a "mandatory attribute" of speeches by politicians, heads of corporations or other large organisations that have a rich, but not always untarnished history. In the research literature, these practices have been correspondingly referred to as institutional responsibility (Green, 2002), corporate social responsibility (Frank, Nezhyba, Heydenreich, 2006) and political responsibility ("Thinking Justice after Marion Young", 2013). Admittedly, these all have a broader interpretation and do not revolve exclusively around a concern with formerly committed acts.

Additionally, problems of interaction with the tragic past enter the research interests of many disciplinary areas, each relying on its own conceptual framework and accordingly presupposing the realisation of its own goals and a solution to specific methodologically and theoretically grounded problems. From this point of view, a study can approach these problems e.g. from socio-philosophical, anthropological or even psychoanalytic outlooks. However, a whole series of concepts used in such an examination have no affiliation to any one discipline: this generates many interpretative 
discrepancies and rifts and also makes it extremely difficult to describe the root phenomena. The concept of historical responsibility can be counted among these.

The difficulties associated with this concept are enumerated by the following: firstly, the problematic division in understanding moral, legal, political and even theological aspects of responsibility, of which discussion is unavoidable at the same time both as a form of ethical obligation and as a duty (in these sense the boundary between responsibility and accountability becomes blurred); secondly, the need to explain the nature of the writing of responsibility in the historical context. This article sets out to clarify these complexities whose purpose is to consider the very possibility of comprehending historical responsibility from the (same) historical perspective, which suggests tracing the sometimes-complicated relations between history, the temporal direction and the ways of conceptualising responsibility. Since such a trajectory of purpose presupposes the solution of multifaceted tasks, the structure of this article will be organised as follows: starting from the complexities associated with the problematisation of responsibility itself, the two most common ways of measuring responsibility will be considered first, avoiding a division into disciplinary and functional affiliation. Then, problematising the possibility of writing responsibility into the historical context, we consider the sources of the contradiction between a consideration of the eternal and unchanging sense of responsibility and the temporal, circumstantial context of its adoption; we analyse the possibilities of assigning responsibility to a chronological extent. Finally, we will provide a conceptual basis for understanding historical responsibility and its consideration in the context of understanding the future.

However, is it necessary to begin our examination with the question of what constitutes historical responsibility itself? Due to the multifaceted nature of the issues that fall under consideration in this context, it is not a simple matter to find an adequate definition. In this article, the following positions will be supported: Historical responsibility presents itself as a complex social phenomenon, presupposing the forging of such connections about the past, the future, and possibly also with bi-directional relations where the realisation of the past in the present, as well as the formulation of the future as a projection of the past, are implied. They are acted out both by individuals and various communities against a backdrop of feelings of guilt, retribution, repentance or recognition of merit, and are represented (mainly) in narrative, commemorative and political practices. In the context of such relations, the boundaries between individual and collective are often eroded, and legal and moral criteria for assessing unfolding events are problematic. Not only does the study of historical responsibility not fit into any one thematic or disciplinary dimension (as we have already said), it also assumes the free inter-transitivity of various discourses from the position of research.

As we can see from this definition, we do not limit our understanding of historical responsibility solely to practices of repentance and apology, but also include in it representations concerning positive responsibility, which involve the topic of merit recognition and the commemoration of outstanding events and figures. In addition, paying attention to the temporal aspects of responsibility, we propose to examine it in the context of both the past and the future (the need for such aspiration, though 
in terms of understanding global memory and the ethics of altruism, is proposed by Sergei Ehrlich (2016).

\section{Two measures of responsibility}

Why is the writing on responsibility in a historical perspective a problem at all? This question is by no means absurd in its salience and relevance, despite the fact that it is easy to answer when referring to the superficiality of problems of historical politics and historical soldiers (Miller, 2016; Finkel, 2011).

At the same time, the complexity that is concealed in the very notion of responsibility with this perspective of foresight remains unremarked upon. The fact is that, with regard to responsibility in the context of history and time, we simultaneously oppose (in the act of imputation) and connect (in acts of acceptance and recognition) something immutable and eternal - for example, human rights, with the (quasi) determination of the deeds and actions committed. For example, S. Ehrlich presents a thesis, in agreement with "an ethics of history based on human rights, which in turn are derived from the Promethean pity for people and from Christian love for one's neighbour." (Ehrlich, 2016, p. 21). Considering this statement, it can be assumed that, through responsibility, the diversity of relative values, in the case of the researcher's stated position, could be called egotistical, to be governed by good as absolute debtlove to one's neighbour and compassion towards all men. Such a position, in turn, presupposes the development of a certain system of requirements and prescriptions, pre-emptive, in the case of the future, and being maintained "retroactively" in the case of the past.

However, regarding such a vision of responsibility, it is necessary to make two important qualifications. The first one assumes that we are dealing with the universalisation and absolutisation of certain values, without relating them to the cultural and historical context, both intentional and not (see, for example: Pakhliuk, 2016, p. 36; Guibernau, 2007). In addition, we should not ignore the consequentialist positions that are widespread in environmental ethics, and examine the problem of historical responsibility, for example, in the context of climate change (Jamieson, 2013; Brennan, Lo, 2016). It should be noted that this line of argument can be not only about moral obligation towards the actions of the participants in the situation, but also about giving the absolute value status of the event itself, thus accumulating in itself the completeness of moral mandates. In the modern Russian context, the Great Patriotic War can be regarded as such an event. (In this connection, a body of research has been compiled "Victory-70: Reconstruction of the Jubilee" [2015]).

The second reservation indicates that these perspectives of responsibility are not the only possible ones and that there are approaches - for example, those of Heidegger, Levinas or Nancy - in which neither the correlation of the idea of good nor the universalisation of value is presupposed. Instead, responsibility receives a different, ontological reading, in which it builds upon the initial foundation of basic human deeds and actions, tied to neither the eternal absolute and immutable senses, or to any prescribed practices. 
Thus, the very concept of responsibility turns out to be the more complex relative to imputation of obligations and recognition of merit, and acquires two dimensions, one of which is established and functions within the prescriptive systems (mainly moral and legal); the other relates directly to evolution and, therefore, infinitely changing human existence. This division leads to the fact that every discussion about responsibility, like every decision to be made, is built on the interoperability of these two dimensions, which sometimes even contradict each other. In this case, we have not only the factor of difference between moral and legal values, but also the impossibility of examining certain events and deeds adequately. At the same time, such "incommensurable" events become authentically historical for us, as they serve both as an expression and a point of problematisation of historical responsibility. In our opinion, through the source and signification of a similar understanding, a characteristic of the Western way of thinking became the trial of Jesus.

\section{Responsibility: between historical and eternal}

In his modest work "Pilate and Jesus," Giorgio Agamben quoting Carl Schmitt remarks that "Christianity is a historical religion, that the 'mysteries' of which it speaks are also and above all historical facts, is taken for granted. If it is true that the incarnation of Christ is a 'historical event of infinite, non-appropriable, non-occupiable singularity', the trial of Jesus is therefore one of the key moments of human history, in which eternity has crossed into history as a decisive point. All the more urgent, than, is the task of understanding, how and why, this crossing between the temporal and the eternal and between the divine and the human assumed precisely the form of krisis, that is, of the juridical trial" (Agamben, 2015, p. 2). This specific position is interesting for many reasons, but mainly because it highlights the borderline or crisis event, as the researcher calls it, which, in reality, involves too many fields of social knowledge concepts customary for us and widely used in ethics - above all, responsibility, guilt, history and repentance. Considering the scene of the trial of Jesus, Agamben investigates the origins of the problem present in the Western way of thinking of the nature of inter-transitivity in history and responsibility, within the fullness and complexity meant by the rationale, including the contradictions between universalist ethics and case law.

Indeed, irrespective of what views - religious or atheistic - one adheres to, the irresolvable inter-transitivities between the historical and the eternal, asserted by the researcher, leave an imprint on many customary phenomena and practices. With such an examination of political differences in connection with history, questions of the ethical and legal dimensions of certain events, one's own methods of judging the past or looking at future prospects, determinism and indeterminism, one way or another accompany any assessment - condemnation and sentencing - become an approximate replica of Pilate's court. In other words, concerning extremely important events, those whose relevance and significance are perceived as enduring and endowed with some higher meaning, we find ourselves in a paradoxical situation: how to make a decision about these higher and enduring values using no other tools 
than those represented in the contemporary arsenal of legal and moral criteria. In connection with this, questions of who should be held accountable for what and to whom, acquire a new and sometimes paradoxical tone. This situation, for example, is responsible for such painful debates about "ancestral territories", the emergence of national states, political values and the consequences of geographical discoveries, say, in the context of postcolonial research, being made circular and insoluble.

For this very reason, the conversation about historical responsibility turns to considering the book Pilate and Jesus. It is precisely responsibility, despite the fact that this word itself is almost not used by Agamben, that is the only and absolute (absolutely insoluble) content of the unfolding confrontation between the temporal and the eternal, the divine and the earthly. It is very likely that such a view may give the impression of an overly complicated interpretation, though in reality only two "kinds" of obligations for making decisions are being dealt with - secular ones, to which legal criteria are applied, and spiritual ones, viewed from the standpoint of religious ethics. In that case, should these criteria be separated from each other and considered separately?

This is the primary difficulty of our consideration. At first glance, it seems that in both cases it is necessary to follow the traditional logic of reasoning that recognises whosoever is guilty only when a number of conditions are met, and only in connection with the violation of certain regulations or prohibitions alleged by one system or the other (moral, legal, etc.). Of course, from this position, the question of whether it is possible to implicate Pilate in the death of Jesus can be approached. Then one of the possible considerations will be to try to resolve the situation within the parameters of the modern legal discourse of guilt, thus avoiding any reference to the metaphysical context of the problem. But the thesis put forward by Agamben (Agamben, 2015; Dusenbury, 2017) in essence is that Pilate does not make a final judgement on execution (does not pass sentence), and thus the question of legitimising the execution of Jesus from the point of view of the law remains open and the whole situation is insoluble. Moreover, religious methods of determining guilt are also untenable, it seems to the researcher that the ontological foundations of the unfolding evangelical drama are deteriorating: "If Pilate, however, has not handed down a legitimate judgement, the encounter between the vicar of Caesar and Jesus, between the human law and the divine, between the earthly and celestial cities, loses its raison d'être and becomes an enigma. At the same time, every possibility of a Christian political theology or of the theological justification of profane power turns out to fail" (Agamben, 2015, p. 57). In Agamben's narrative, Pilate is portrayed as a man tormented both by his own inability to make a decision and the impossibility of ridding himself of the pressure of circumstances and the demands of the social context to which the trial must conform, and turns out to be "not entirely" responsible if the traditional logic of reasoning is followed.

However, in his criticism of Agamben's research, David Lloyd Dusenbury (2017) argues that Pilate nevertheless passed the verdict; moreover - "This is the tragic interest of Pilate's psychology in the canonical gospels: he declares Jesus to be innocent, but he orders the crucifixion. In terms of Aristotle's Poetics, Pilate kills 
Jesus like Medea kills her children: consciously" (p. 12) (italics are the author's - D.T.). It would seem that the problem is simply resolved, because the main criterion that makes a person responsible - consciousness - is observed. However, instead, the researcher pays attention to another dilemma, interpreting from early Christian texts: "The Roman prefect is neither crazed nor deceived. [That is, regarding an ability to bear responsibility - D.T.] And, because of this, the question - however misdirected can be raised: is Pilate's decision to crucify the Son of God an act of consummate impiety (since Jesus is not only innocent, but 'the light of the world') a, or a sign of reluctant piety (since Jesus, nevertheless, 'must be lifted up' for the salvation of the world) ${ }^{\mathrm{b}}$ ?" (In this passage, the author refers to the Gospel of John. When quoting, these references were designated by us as ${ }^{a}$ and ${ }^{b}$. ${ }^{a}$ : John 8:12, cf. 12: 34-36, 46. And for "Son of God": John 19: 7; ': John 3: 14-15).

When put in this way, the issue of responsibility is radically changed, since it is not the guilt itself that is at the centre, but rather the "quality" of this guilt. Moreover (Agamben also draws attention to this), the messianic character of the decision is highlighted. Then the actions of Pilate are already simultaneously both intentional and predestined, although, this circumstance no longer allows responsibility to be discussed solely in the secular context and with the traditional logic of reasoning. In other words, using the "messianic perspective" interweaves the secular chronology of events into a timeless metaphysical context.

Indeed, therein lies the paradox insists on by Agamben: when we consider Pilate's decision, there is not and can be no responsibility arising without a mutual interweaving and amalgamation of the temporal and eternal. Consequently, it may be noted that it is not the question of whether or not the procurator of Judea was able to render a judgement that is being dealt with, but rather whether or not we ourselves are able to decide on what happened by using this criteria and means. "The hermeneutical canon that we will maintain is, rather, that only as historical character does Pilate carry out his theological function and, vice versa, that he is a historical character only insofar as he carries out his theological function. Historical character [personaggio] and theological persona, juridical trial and eschatological crisis coincide without remainder and only in this coincidence, only in their 'falling together', do they find their truth" (Agamben, 2015, p. 35).

This tension between the historical as temporal and worldly, and historical as eternal, which causes their mutual infiltration of each other, has had a decisive impact on the formation of our modern (Western-style) notion of responsibility, in all its ambiguity and multidimensionality. If Agamben supposes that Pilate's legal decision was necessary for a kind of theological legitimisation, then in our ordinary life we are dealing more with the opposite statement: in order for some legal or moral decision to acquire meaning, it must acquire a "metaphysical" legitimisation within the event. The point, therefore, is not about separating the wheat from the chaff - separating responsibility into faults: moral, legal and political, but about the possibility or impossibility of writing the very principle of responsibility with the inherent articulations of truth and justice in the earth's historical perspective. Such a statement of the question itself is problematic indeed, what exactly is meant by it? 


\section{Responsibility and chronological expanse}

The simplest method for understanding history, to which the Agamben interpretation of the trial of Jesus seems to refer, is to present it as a way of isolating relations within an era or event. In other words, a chronology is needed into which some situation are slotted, or vice versa, a chronology is created as a consequence of the situation different interpretations are possible here. The familiar division of the time of the entire world history into the periods "before the birth of Christ" and "after" is the clearest example of this understanding. But how should historical responsibility be presented? In our opinion, there are two different approaches.

The first will consist in trying to describe the historicity of responsibility, i.e., to construct history of responsibility itself. It could be described as the most traditionally academically. Then we will proceed from the need to write responsibility in the chronology already existing, based on the fact that some ideas and some practices imputations, recognition, pride, repentance, commemoration or oblivion - will be examined as establishing and transforming in time and space, through eras and cultures. For example, Alexei Miller, in his article "The politics of memory in post-communist Europe and its impact on the European culture of memory" (Miller, 2016) presents the causes, formation and development of two cultures and memory politics at the end of the $20^{\text {th }}$ and the beginning of the $21^{\text {st }}$ centuries each establishing its own understanding of responsibility. Thus, the researcher notes that for Western European countries "the consensus on the Holocaust in itself was of great importance. He excluded the construction of national historical narratives in this part of Europe in which the primary loser would be the titular nation. It was impossible to demand preference, referring to previous suffering. At the centre was the question of personal responsibility and the measures that should be taken to prevent the recurrence of crimes such as the Holocaust "(Miller, 2016, p. 112). At the same time, Eastern European countries have a completely different understanding of the role of their citizens in the history of the twentieth century and instead of a consensus on common responsibility, their understanding is characterised as "export of guilt" (Miller, 2016, p. 116).

Therefore, in setting the corresponding task, the transformations of responsibility in history will be possible to be described and analysed for trends and divergences from them, in order to emphasise, depending on the chosen approach, some generalising teleological line or the fundamentally random nature of occurring developments, based on for example the methodology of Michel Foucault. Certainly, in this case there is always a choice: either the creation of an individual history of responsibility will be attempted, or - much more difficult - the tracing of a genealogy of responsibility. An obstacle in committing to this trajectory arises after turning to various concepts, historical and philosophical endeavours - or to the archives of quotes and practices: the problem with this practice is that it will scatter the logic of the initially chosen trajectory. In other words, this approach shows how responsibility is constituted in the past - allowing us to identify the various premises for such a constitution, for example, political or economic - but does not say anything about how the chronology itself is constituted through the prism of responsibility. 
In this case, we do not mean the problem of giving meaning to the events inscribed in the chronology, which is precisely what this approach aims at solving. As a result, there is always a danger that, starting from some of the most popular ways of understanding the human relation organisation we call responsibility, we will reconstruct the dynamics of this organisation in the past, giving it some arbitrary duration in time and ascribing it meanings common to us in our modern context. In like manner, the history of all things and phenomena can be created. However, in such a history, the crises of the temporal and eternal, deliberate and predestined, legitimate and illegitimate as such are not understood or problematised.

The second way is to try to define some perspective, from which responsibility with an unchanging value throughout time can be discussed, in the same way that some self-same idea or practice places a limit on the extent of the self-evidence of its own value, making any additional attempt towards a "dictionary" definition pointless. So, when it is said that it is impossible to overestimate the significance of the discovery by Fleming of the discovery of penicillin or the discovery of America made by Columbus, it seems to us that it is about the same understanding of responsibility. This understanding allows transitions between the comprehension of responsibility, as relating to private life and the responsibility extended to "wider" communities, to be made - for example, citizens of one state or persons united by a common history.

Indicative in this respect is the text of Vladimir Yakovlev entitled "My grandfather Chekist and murderer", in which the author shares his experience of his own moral trauma in connection with the discoveries of his family history and encourages readers to responsibly rethink the past, advocating a broadening of all residents' understanding within the country: "We often think that the best way to protect ourselves from the past is not to disturb it, not to dig into the family history, not to dig into the horrors that have happened to our relatives. It seems to us that it is better not to know. In fact, it is worse. Much worse. What we do not know continues to influence us, through childhood memories, through relationships with parents. Simply, without knowing, we do not recognise this influence and are thus powerless to resist it." (Yakovlev). It should be noted that this publication caused two radically different types of reader reaction: a general agreement with the call for responsible rethinking of the past, and radical denial, as well as scepticism about the authenticity of the narrative. In fact, such reactions are both indicative and predictable, since they reflect the poignancy and sensitivity associated with the task of rethinking the history of the twentieth century in contemporary Russian society.

For that very reason, any determination of the meaning, explanation or interpretation of responsibility becomes meaningless: this will only complicate the already developed system of relations, overload it with "superfluous" meanings and confuse both those who make the decision and those who must be held accountable. Let us recall the classic example already given of Eichmann's recognition of moral guilt, but denial of criminal guilt (Arendt, 2006). Pilate's court and all subsequent courts and decisions, becoming milestones in the continuous chronology of mankind's responsibility, no matter whether it is about protecting the environment or about past episodes of injustice, violence or exploitation, address self-evidence, and at the same 
time always need to be explained or correlated with the place in time. Derrida saw this problem (with regard to the politicisation of forgiveness), in the following way: "It is between these two poles, irreconcilable but indissociable, that decisions and responsibilities are to be taken" (Derrida, 2005, p. 45).

When referring to this text, in the context of our consideration, it is necessary to pay attention to the following. Listing the various politicised practices of recognising the guilt and turmoil of the traumatic past and substituting forgiveness (that is, practices that most often fall under the definition of historical responsibility), the researcher uses the notion of historical ecology (Derrida, 2005, p. 45). This concept can be useful for understanding historical responsibility because it enables the limitations of the two approaches described above to be overcome. Therefore, if we proceed from the most general definition of ecology as the interconnection of elements with each other and the environment that organises these interrelationships, and depends itself on their organisation (see, for example, Sarkar, 2016), so with such an interpretation responsibility becomes the very method of organising the interrelationships of various elements of history (history as an environment): meanings, people, dates, events, intentions, goals, motives and results, both in the past and in the future. This very way of organising interrelationships is both self-evident and indefinable; the discussion, however, is not about an unchanging meaning, which could also be called substantivisation, at the basis of responsibility, and it is not being attempted here to write some events into the available chronology to the detriment of the rest that do not fit into a predetermined framework. It is noted that the understanding proposed here turns out to be close to the notion of the "signature" proposed by Agamben (2009).

\section{Historical responsibility as the unfolding of meaning}

But what is signified by the understanding of historical responsibility as an organisation of event interconnections, people and phenomena? On what principles can this interconnectedness be established? In order to answer this question, we need to turn to an ontological approach to understanding responsibility. In general, this approach assumes that resorting to responsibility not only does not imply the existence of any substantivist understanding, but is born every time from a single, concrete act of human interaction, becoming the very way of realising these interactions (as was noted above, referring to the concept of historical Ecology). (On ontological approaches in the understanding of responsibility, see: Raffoul, 2010). From this point of view, it must be said that responsibility does not arise after the fact, but becomes inherent in the event itself. With this understanding, historical responsibility is not bound by the need to be fully isolated in the existing chronology or completely governed by any external prescriptions and restrictions, say, in space and time. For example, in this context, responsibility could be said to begin at some defined moment in time, and end after the passing of a certain time period, in connection with, for instance, the expiration of a statute of limitations, or in connection with the advent of punishment or in finding those answerable in a different situation of political or legal status (as we can see in the case of criminal liability). 
The investigation conducted by Denis Karagodin of the circumstances surrounding the shooting of his great-grandfather, Stepan Ivanovich Karagodin serves as an illustrative example of this position. The researcher established the name and title of all persons involved in this shooting, beginning with those who directly committed the act and those who supported it and ending with the city authorities who signed the death warrant. It should be noted that the progress and results of the investigation were widely covered by Internet publications, and its author started an open Internet page for posting the latest news and updates in the investigation (http://blog. stepanivanovichkaragodin.org/). The interest generated by this story can be explained for several reasons: firstly, clarification of the tragic fate of people's ancestors and the identification of specific culprits has never become a widespread Russian practice; Secondly, in this case it is completely impossible to discuss criminal responsibility in full (following the expiry of the statute of limitation and due to a lack of living culprits). However, the very relations of responsibility themselves do not disappear with time, thus marking events and people included therein.

Of course, in this case it is impossible not to analyse the question of whether such responsibility extends likewise to descendants. Since this topic deserves a separate study, it will not be examined in detail here; it is noted that the discussion in this case cannot be about the responsibility of descendants for the past actions of their ancestors, but instead must concern the responsibility for comprehending and representing the events of the past. It is worth noting that in an interview with channel AT2, on the question of whether he will acquaint the descendants of the accused with the results of the investigation, Denis Karagodin responded as follows: "Descendants (if any) have no obligation towards me and do not owe me anything; the same as I owe them nothing. I do not track them in principle; their appearance in the "study" is always a kind of surplus to requirement $-/ . . . /$ they are like an echo of an investigative threadnothing more. /..../ disturbing them is unacceptable - they are not guilty of anything. This is essentially my position" ("To call the names of executioners", 2016).

On November 20, 2016 Denis Karagodin received a letter ("Civil Accord") from the "granddaughter of Nikolai Ivanovich Zyryanov - the executioner of the Tomsk City Department of the NKVD." Expressing feelings of regret and shame over newly discovered facts in her family history, the author of the letter notes: "So now it comes out that in one family there are both victims and executioners ... It's very bitter to realise this, it's very painful... But I will never disown my family history, whatever it may be. Knowing that neither I, nor all the relatives whom I know, remember and love had anything to do with these atrocities that occurred in those years will be a solace to me" ("Civil Accord", 2016). In the responding letter, Denis Karagodin suggests extending a hand of reconciliation and "nullifying the whole situation" by not distributing the tragedy and the blame to the descendants ("Civil Accord", 2016). The new situation of reconciliation must now be built upon the knowledge of past events that have occurred and the principal agreement on their value.

But, in this case, the very situation under discussion about historical responsibility changes, implying that we will consider history itself as responsibility. In this understanding, we again will conceptually proceed from an ontological way 
of understanding responsibility. Then, with a similar perspective of examination, the main task of the research becomes not only the analysis of objective facts, dates, conditions, prescriptions and norms, but also the establishment of the ethical nature of current events. This evaluation is a paradox in that the timelessness of the idea of responsibility and the inscrutability of its practices into the existing Earth chronology are deprived of any external criteria for measurement, imputation and evaluation. As such, historical responsibility becomes an insoluble problem, determined only by the connecting objects themselves, primarily people and events.

In the opinion of the researchers, the most appropriate concept of responsibility for this understanding is the concept of "responsibility for existence" J.-L. Nancy (1999). Researcher denied the understanding of the responsibility as some prescription and arguing that "We exist as this responsibility; that is, in Heidegger's words we ek-sist, we are exposed to one another to the world - the world which is nothing but this very exposure. Existence is responsibility for existence" (p. 8). Based on the views of the researcher, it can be said that the very constituting of historicity is no longer an external supplement to responsibility like a predicate, as, for example, a line of chronology or a successively unfolding scientific theory, but becomes the very method of its (responsibility) becoming. At the same time, this becoming is what Nancy himself calls the responsibility of sense, where the sense is "the commitment the several between each other" (Nancy, 1999, p. 8). The researcher notes the fundamental infinitude and untransmissibility of a sense connoting something that has been formed, is already taking place or which possesses substantial completeness. In contrast, Nancy refers to the fact that sense is always expressed through the other, and that this, in turn, depends on the readiness of the person transmitting the thought to always be accountable for it (Nancy, 1999, p. 7; p. 9).

The becoming of sense is in fact, the way in which historical responsibility is phenomenalised in various social practices. The problem of the context of the future, which has hardly been touched upon in this discussion, is indicative of a greater attachment not to predicting the consequences, but towards the meanings that may arise in connection with deeds to be realised in concrete actions or events. True, in this case, we need to pay attention to the distinction between the concept of historical responsibility as the establishment of meaning and messianism, where the latter again refers us to the substantivist notion and the external justifications for history and chronology.

\section{Historical responsibility as an aspiration for the future}

The problem of historical responsibility as an aspiration for the future is developed to a lesser degree. Risking the use of the phrase, the imagination of the future, always seems less painful as a rule; therefore, the projection thereof produces a somewhat smaller emotional reaction. We can talk about such methods of presenting responsibility in two ways: the global, which most often involves understanding the responsibility of all mankind (which has already been touched upon in relation to environmental ethics and climate studies), and the local, which tends to be associated more with the notion of messianism. On the notion of messianism, we should examine in a little more detail. 
What is messianism? In connection with this discussion, Peter J. S. Duncan offers the most appropriate definition of messianism: "The proposition or belief that a given group is in some way chosen for a purpose. Closely linked to this is the view that the great suffering endured by the group will lead somehow to the redemption to the group itself and possibly of all humanity" (Duncan, 2000, p. 1).

Thus, conversation in the context of historical responsibility can only go so far where obligations are concerned that are accepted by any community for the achievement or establishment of some desired state, say, economic, political, religious or legal, both within itself and other communities. Ideas in the secular variations of messianism, can feature liberal worldviews of permanent revolution, ethnic unification, the construction of an open market, etc. In short, there are many versions, each of which presupposes the establishment of some uniform order, or the formation of social unity, initially based on ontological premises, for example: lineage, the past, or even an idea broadcast in scientific or political theories. At the same time, the task of establishing this order demands the exertion of efforts from a single, "elected" figurehead. (See, for example, Duncan, 2000; Merkel, 2008). For the formation and legitimisation of such concepts, it is necessary to reference historical grounds which may be derived from the declaration of past inherent merits, recognition of their significance (achievements, chosenness, righteousness), greatness and radical difference from other communities, which, therefore, cannot derive such self-positioning. Note that this form of messianism is associated not so much with the figure of the Messiah as with the Mission. The community that has laid such obligations upon itself ascribes characteristics of the Messiah to itself.

But messianism can take a different form, resulting from the recognition of one's own (global, universal) guilt, distributable to all humanity - if the discussion, for example, is about ecological ethics, or the need to preserve the memory of crimes against humanity. In the context of historical responsibility, this approach is manifested not only in religious, but also in purely secular interpretations. The opposite way of interpretation of messianism in this register is becoming obligatory in some communities: ethnic, religious or gender group, etc. where members of different communities represent their tragedy as something unique (Finkel, 2011).

But when it comes to the future, it should be borne in mind that the past, in the context of the event interpretation, can be perceived as an independently operating player, and in its metaphorical form, plunges one into a peculiar eschatology of responsibility, which in an instrumentalised way solidifies into real actions or processes. In this way, for example, we can talk about archives. For example, Randall C. Jimerson (2007) says: "In addition to protecting the rights and interests of all citizens, archives preserve vital aspects of cultural heritage. These dual responsibilities give archivists significant power, not only over questions of recordkeeping in today's society but for future generations. Such power carries an obligation to employ it for positive purposes, as archivists search for a role to play for the benefit of all people in society" (p. 254). However, if above we talked about the link to the past and the events that have already occurred to date, then, with regard to the future, such a linkage disappears. In this regard historical responsibility is viewed as a retroactive act imputing or acknowledging 
the imminent pronouncement of guilt; that is, after the execution of certain planned acts as a means to an ends had been achieved.

\section{Conclusion}

Thus, in this article, we turned to the solution of a rather difficult task - to study how historical responsibility is conceptualised in the historical perspective. The very formulation of such a task, as well as the body of problems, issues and contradictions that had to be tackled during our consideration, showed the fundamental nonlocalisability of the problem of historical responsibility in some separate disciplinary and discursive boundaries, as well as its fundamental irreducibility to a limited set of practices. This means that we are dealing with a way of organising some people, events and phenomena into a single semantic field, the parameters of which are simultaneously mobile. Moreover, now we can say that the writing of responsibility in the historical perspective does not mean how it should be expected, nor the fulfilment of an act of methodological reduction, or the fixing of certain events as points on the time scale. On the contrary, historical responsibility is nothing other than a meaningful unfolding and becoming of this very historical perspective, which covers looking back or seeking to look ahead, beyond the horizon of events, we conceive and cast our obligations into eternity.

\section{References}

Agamben, G. (2015). Pilate and Jesus. Stanford: Stanford University Press.

Agamben G. (2009). Theory of Signatures. In Agamben G. The Signature of all things: on method. NY: Zone books.

The Act of Civil Consent. (2016). Retrieved from http://blog. stepanivanovichkaragodin.org/?p=11119\#more-11119

Arendt H. (2006). Eichmann in Jerusalem. London: Penguin books.

Brennan A., Lo Y.-S. (2016). Environmental Ethics. The Stanford Encyclopedia of Philosophy (edited by E.N. Zalta). Retrieved from https://plato.stanford.edu/archives/ win2016/entries/ethics-environmental/

Derrida J. (2005). On Forgiveness In Derrida J. On Cosmopolitism and Forgiveness. London and New York: Routledge.

Duncan P. J. S. (2000). Russian Messianism: Third Rome, Revolution, Communism and After. London: Routledge.

Dusenbury D. L. (in press). The Judgment of Pontius Pilate: a Critique of Giorgio 
Agamben. Journal of Law and Religion. Preprint version retrieved from https:// www.academia.edu/13277730/The Judgement of Pontius Pilate A Critique of Giorgio Agamben Journal of Law and Religion 2017

Erlich S.E. (2016). Global Memory of the Information Society: Ethics, Identity, Narrative. Historical Expertise, 3, 11-32.

Finkel E.V. (2011). In Search of Lost Genocides. Pro et Contra, May-August. Retrieved from http://carnegieendowment.org/files/ProetContra 52 123-143.pdf

Frank P., Nezhyba J., Heydenreich C. (2006). Taking Corporate Social Responsibility Seriously. Ekologický právní servis - Environmental Law Service, Brno.

Global Memory: a Culture of Historical Responsibility in the 21st century. (2016). Historical Expertise, 3, 7-10.

Guibernau M. (2008). National Identity versus Cosmopolitan Identity. In D. Held, H.L. Moore and K. Young (eds.). Cultural Politics in a Global Age, 148-156. Oxford: Oneworld.

Green M.J. (2002). Institutional Responsibility for Global Problems. Philosophical Problems, 30 (2), 79-95.

Jameson D. (2013). Climate Change, Consequentialism, and the Road Ahead. Chicago Journal of International Law, 13(2). Retrieved from http://chicagounbound. uchicago.edu/cgi/viewcontent.cgi?article=1375\&context=cjil

Jimerson C.R. (2007). Archives for All: Professional Responsibility and Social Justice. The American Archivist, 70, 252-281.

Johnson G.F., Michaelis L., ed. (2013). Thinking Justice after Marion Young. Toronto: University of Toronto Press.

Merkel W. (2008). Democracy through War? Democratization, 15 (3), 487-508.

Miller A. (2016). The Politics of Memory in Postcommunist Europe and its Impact on the European Culture of Memory. Polity, 1, 111-121.

Nancy J.-L. (1999). Responding for Existence. Studies in Practical Philosophy, 1 (1), 1-11. DOI: 10.5840/studpracphil1999112

Pakhlyuk K.A. (2016). Global Memory Culture: in Search of a Teleological Perspective. Historical Expertise, 3, 33-49. 
Raffoul F. (2010). The Origins of Responsibility. Bloomington, Indianopolis: Indiana University Press.

Sarkar, S. (2016). "Ecology", The Stanford Encyclopedia of Philosophy (edited by Zalta E.N.). Retrieved from https://plato.stanford.edu/archives/win2016/entries/ecology/

"Nazvat' imena palachey" [To Call the Names of Executioners] (2016). Retrieved from http://tv2.today/TV2Old/Nazvat-imena-palachey

Victory-70: the Reconstruction of the Anniversary(2015). Ed. Gennady Bordyugov. Moscow: Airo-XXI.

Yakovlev V. (2016). "Moy ded - Chekist i Ubiytsa" [My grandfather - Chekist and Murderer]. Retrieved from Facebook https://www.facebook.com/1206441856087060/ photos/a.1214617398602839.1073741828.1206441856087060/1214765738588005/ ?type $=1 \&$ theater 